Research Article

\title{
Credit Evaluation Model of Road Transportation Enterprises Based on the Combination Weighting Method
}

\author{
Yu-shan Hu iD and Chun-lei Zhu ii \\ School of Transportation Engineering, Dalian Maritime University, Dalian 116026, China \\ Correspondence should be addressed to Yu-shan Hu; 1120180366@dlmu.edu.cn
}

Received 17 October 2020; Revised 2 December 2020; Accepted 11 December 2020; Published 13 January 2021

Academic Editor: Yang Li

Copyright (C) $2021 \mathrm{Yu}$-shan $\mathrm{Hu}$ and Chun-lei Zhu. This is an open access article distributed under the Creative Commons Attribution License, which permits unrestricted use, distribution, and reproduction in any medium, provided the original work is properly cited.

\begin{abstract}
In the road transportation industry, the high risk of default by enterprises will have a serious impact on consumer interests and market order. To improve the scientific nature of the credit evaluation of road transportation enterprises, this paper establishes a credit evaluation model based on the combination weighting method, considering the information volume, volatility, and difference of the road transportation enterprises data and using normalized constraints of maximum variance to determine the combination weights. The model fully considers the degree of difference between the indicators and makes up for the deviation of the single weighting method. Finally, the paper makes an empirical analysis of 115 road transportation enterprises in a certain province of China and verifies the rationality of the combination weighting model. The results show that the credit level of a road transport enterprise in a certain province is at a medium level. Strengthening the supervision and examination of the management, qualification, and safety production capacity of the enterprise can further improve the credit level of the road transportation enterprise.
\end{abstract}

\section{Introduction}

The road transport industry is a basic industry that affects the national economy and plays an important role in economic development. It has the characteristics of many points, long lines, and wide coverage. The contradiction between the mobility of the road transport industry and the localization of management results in the high difficulty of credit supervision in the industry, which leads to frequent dishonesty in the industry. Thus, the credit evaluation of road transport enterprises has attracted much attention.

In the process of credit evaluation, the weight of each evaluation indicator reflects the importance of the indicator, which also relates to the final ranking results of the evaluation objects. The existing mature credit evaluation systems, such as Standard \& Poor's, Moody's, and Fitch's, are based on the economic activities of corporate financing loans [1-3]. They mainly evaluate the financing and loan ability of the enterprise through the financial level and operating condition of the enterprise. However, the credit evaluation of road transportation enterprises should pay more attention to the factors with characteristics of the road transportation industry, such as the safety production capacity of the enterprise, rather than the evaluation of loan capacity. Therefore, it is necessary to allocate weights to the evaluation indicators that reflect the character of the road transportation enterprises; otherwise, the evaluation results of the enterprises will be biased and cannot reflect the industry characteristics. Consequently, a reasonable weight distribution method of indicators is very important in credit evaluation research, which will affect the scientific nature and rationality of the evaluation results.

1.1. Literature Review. There are mainly three kinds of weighting methods for credit evaluation: subjective weighting, objective weighting, and combination weighting method. The subjective weighting method is a means for experts or scholars to determine the subjective weight according to their information or preferences. For example, $\mathrm{Li}$ et al. established an e-commerce credit evaluation model by using the analytic hierarchy process (AHP) and made an 
empirical analysis of 30 e-commerce enterprises [4]. Some experts use the fuzzy analytic hierarchy process (FAHP) to solve various multiattribute decision-making problems in the engineering field [5-7]. Li et al. proposed an improved evaluation method of an electromagnetic loop network decoupling scheme based on the fuzzy analytic hierarchy process (FAHP) [8]. Some papers address that the subjective weighting method has a certain degree of inconsistency, which has inherent difficulty in assigning reasonable subjective weights [9-11]. Different from the subjective weighting method, the objective weighting method is a means that calculates the index weight by establishing a mathematical model using the objective information. For example, Zhang et al. used the entropy method for objective weighting and established a scientific and technology evaluation model [12].

The objective weighting method obtains weights based on the actual data, so it is more susceptible to the influence of sample data. Furthermore, different objective weighting methods have different data tendencies and reflect different data laws. Therefore, some scholars proposed a combination weighting method, which combines the weights obtained by different single weighting methods to obtain the combination weights. For example, Meng and Li used G1, G2, and entropy methods to establish an energy efficiency evaluation model [13]. Zhao et al. proposed a combined weighting method based on the expert scoring method and the interval center point distance method, which illustrates the onesidedness of the independent weighting of subjective and objective weighting methods [14]. Chao and Fu used three weighting methods to build a combination forecasting model [15]. Chen and Yang combined the analytic hierarchy process (AHP) and factor analysis to establish a credit evaluation model [16]. Li et al. proposed a two-stage approach by combining multiobjective optimization (MOO) with integrated decision-making (IDM) to address the problem of combined heat and power economic emission dispatch (CHPEED) [17]. In the study of the combination weighting model, some weighting methods are used casually in the process of weight distribution. Thus, some scholars study and improve the weighting method of the combination weighting model. For example, Chen proposed a new optimal combination weighting method based on the sum of squares of deviations in multiattribute decision-making [18]. Sun and Bao combined the method of determining the weight of the rough set and the expert weighting method and put forward the subjective and objective combination weighting methods based on the principle of variance maximization [19]. Chi et al. combined the subjective and objective weighting methods with the idea of maximum consistency of the evaluation results to determine the optimal combination weight [20].

In the research of the combination weighting method, scholars usually use the subjective weighting method to reflect the experience of experts and the objective weighting method to reflect the differences and laws of data, and the combined weight is obtained by the weighted average of the subjective and objective weighting results. However, in the process of subjective weighting, its flexibility and variability often lead to the disunity of the results. Therefore, how to determine a reasonable combination weight so that the evaluation index can comprehensively reflect the law of data and can scientifically combine the single weighting methods is the problem to be solved in this paper.

For this, this paper constructs a credit evaluation model of road transport enterprises based on the combination weighting method. Considering the characteristics of information volume, volatility, and difference of the credit data based on road transport enterprises, the objective weighting methods, entropy, criteria importance through intercriteria correction (CRITIC), and variation coefficient are used to reflect the road transport enterprise data law from three dimensions of data characteristics, respectively. According to the idea that the combined weights of all indicators get the largest total variance of all evaluation objects, the multidimensional combination weighting model based on variance maximization is established, and the optimal combination weight is determined. Meanwhile, an empirical analysis is carried out based on the road transport enterprises in a certain province of China, and the rationality of the combination weighting model is ensured by the cosine test and the order preservation test.

1.2. Contribution of This Paper. The main contributions of this paper are the following two-fold:

(1) A multidimensional combination weighting model: a multidimensional combination weighting model is constructed to comprehensively reflect the law of data. Considering the characteristics of information volume, volatility, and difference of the credit data based on road transport enterprises, the objective weighting methods, entropy, CRITIC, and variation coefficient are used to reflect the road transport enterprise data law from three dimensions of data characteristics, respectively. The combination of the three objective weighting methods avoids the problem that the existing combination weighting method often fails to obtain a unified result by using the subjective weighting method.

(2) A variance maximization method: a variance maximization method is constructed to solve the multidimensional combination weighting model. According to the idea that the combined weights of all indicators get the largest total variance of all evaluation objects, the multidimensional combination weighting model based on variance maximization is established, and the optimal combination weight is determined. The principle of variance maximization makes the evaluation results of evaluation objects more discrete, and the differentiation of evaluation results between evaluation objects is higher.

1.3. Organization of This Paper. The rest of this paper is structured as follows: Section 2 introduces the multidimensional combination weighting model based on variance 
maximization, Section 3 provides the empirical study, Section 4 analyzes the empirical results, and Section 5 makes the conclusions and prospects.

\section{Multidimensional Combination Weighting Model Based on Variance Maximization}

2.1. Problem Description. Considering the characteristics of road transport enterprises, the credit evaluation system is established from four aspects: basic quality, management qualification, production safety, and credit management level. Among them, enterprise safety in production is the criterion layer that reflects the characteristics of the road transport industry. The occurrence of major traffic accidents will have a serious impact on the credit of enterprises, so the safety situation is an important factor for road transport enterprises.

In the process of establishing a credit evaluation model, the weight of the evaluation index should be determined according to the importance of the evaluation index. The weight of the index and the structural relationship between the weight vectors directly affect the evaluation results. Therefore, it is quite important to allocate the weight of the evaluation index reasonably. For the subjective weighting method, the results of scoring by different experts are often very different, thus the subjective arbitrariness is strong. Therefore, this paper chooses three objective weighting methods, entropy, CRITIC, and variation coefficient, to evaluate the data of the index from three dimensions of data information, volatility, and difference. Among them, the entropy method reflects the amount of information of the index, the CRITIC method reflects the impact of data volatility on the index, and the variation coefficient method reflects the difference between indicators. The combined weight is determined based on the maximization of variance between indicators. The greater difference of the index between the evaluation objects corresponds to the greater influence of the index on the evaluation results, and such an index should be distributed with a greater weight. Thus, the variance of the normalized constraints is maximized, and a linear programming model is constructed to maximize the total variance of all indicators for all evaluation objects. The principle of variance maximization makes the evaluation results of evaluation objects more discrete, and the differentiation of evaluation results between evaluation objects is higher. The proposed model framework is shown in Figure 1.

\subsection{Multidimensional Objective Weighting Model}

2.2.1. Objective Weighting Model: Entropy. Entropy determines the objective weight of the index from the dimension of the information volume. The amount of information contained in the evaluation index can be measured by calculating entropy. When the entropy value of the index is more than $95 \%$, it can be ensured that the evaluation index system can reflect most of the original information.

Let $f_{i j}$ and $x_{i j}$ be the proportion of the membership degree of the $j$ th evaluation object on the $i$ th index and the standard score of the $j$ th evaluation object on the $i$ th index. Let $M, m, n$, and $w_{i}$ represent the entropy of the $i$ th index, the number of evaluation objects, the total number of evaluation indicators, and the entropy weight of the $i$ th index.

The steps of the entropy are as follows:

Step 1. Calculating the proportion of the membership degree of the index [21]:

$$
f_{i j}=\frac{x_{i j}}{\sum_{i=1}^{m} x_{i j}} .
$$

Step 2. Calculating the entropy $M$ of the $i$ th index and the entropy weight $w_{i}$ of the $j$ th index [21]:

$$
\begin{aligned}
M_{i} & =-\frac{1}{\ln (m)}\left[\sum_{j=1}^{m} f_{i j} \ln f_{i j}\right], \\
w_{i} & =\frac{\left(1-M_{i}\right)}{\left(n-\sum_{i=1}^{n} M_{i}\right)} .
\end{aligned}
$$

2.2.2. Objective Weighting Model: CRITIC. The CRITIC determines the objective weight from the dimension of data volatility. The standard deviation of the index is used to show the volatility of the data, and the correlation between the indices is used to show the conflict.

Let $r_{i j}, x_{i k}, x_{j k}, \overline{x_{i}}$, and $\overline{x_{j}}$ be the correlation coefficient between the $i$ th index and the $j$ th index, the standardization score of the $k$ th evaluation object on the $i$ th index, the standardization score of the $k$ th evaluation object on the $j$ th index, the average score of the $i$ th index, and the average score of the $j$ th index, respectively. Then, the steps of the CRITIC are as follows:

Step 1. Calculating the correlation coefficient between indicators $i$ and $j$ [22]:

$$
r_{i j}=\frac{\sum_{k=1}^{n}\left(x_{i k}-\bar{x}_{i}\right)\left(x_{j k}-\bar{x}_{j}\right)}{\sum_{k=1}^{n}\left(x_{i k}-\overline{x_{i}}\right)^{2}\left(x_{j k}-\overline{x_{j}}\right)^{2}} .
$$

Step 2. Calculating the amount of information $C_{i}$ and weight $\beta_{i}$ of the $i$ th index [22]. Among this, $\beta_{i}$ denotes the standard deviation of the $i$ th index:

$$
\begin{aligned}
& C_{i}=\delta_{i} \sum_{j=1}^{n}\left(1-r_{i j}\right), \\
& \beta_{i}=\frac{C_{i}}{\sum_{i}^{m} C_{i}} .
\end{aligned}
$$

2.2.3. Objective Weighting Model: Variation Coefficient. The variation coefficient determines the objective weight from the dimension of data difference. The greater variation coefficient of an index corresponds to the greater explanatory power in measuring the gap between the evaluated objects. 


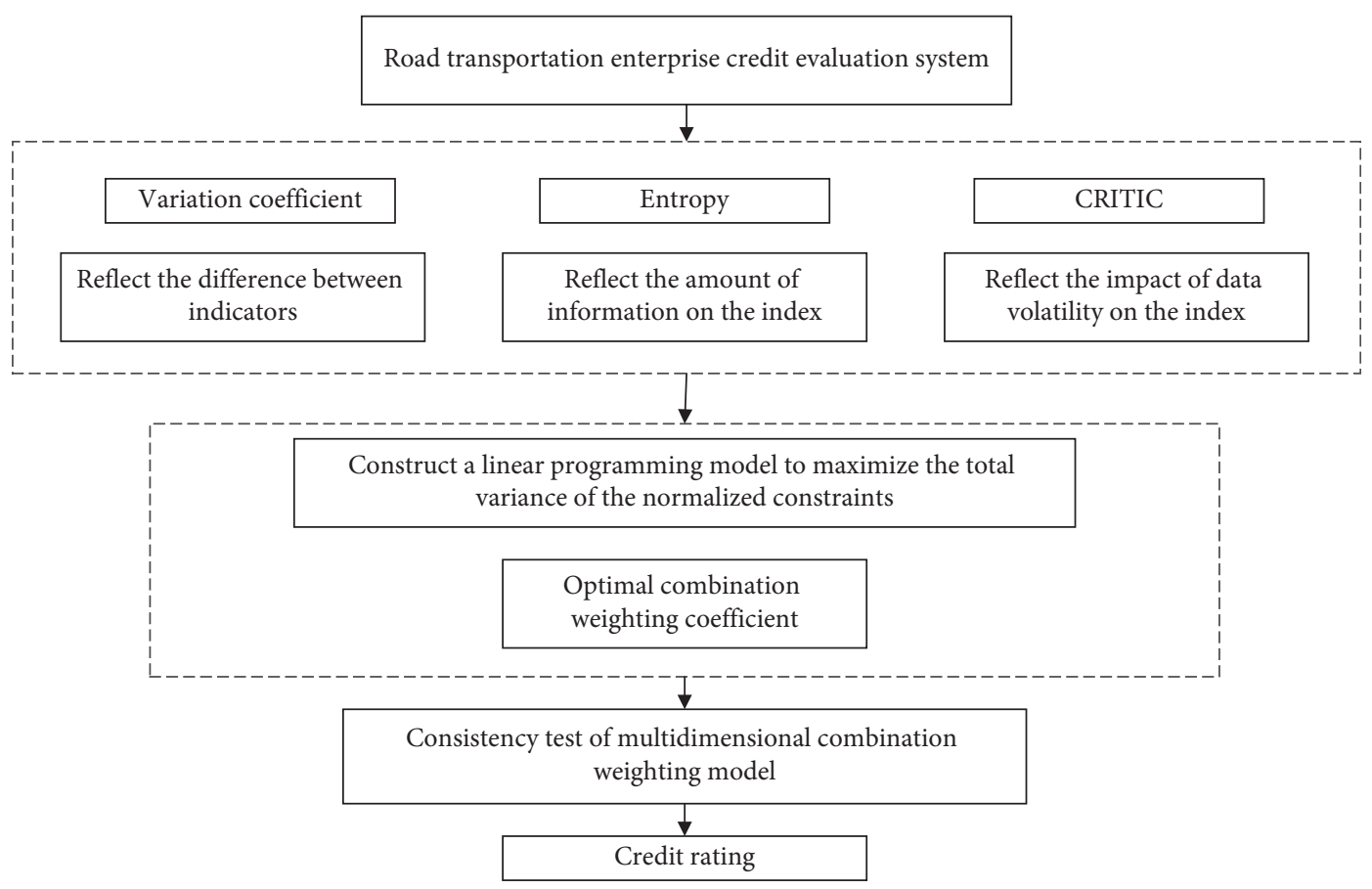

FIGURE 1: Flowchart of the proposed combination weighting model.

Let $\alpha_{i}, x_{i j}, m$, and $n$ be the variation coefficient weight of the $i$ th index, the standard score of the $i$ th enterprise on the $j$ th index, the total number of enterprises, and the total number of indicators, respectively.

The steps of the variation coefficient are as follows:

Step 1. Calculating the variation coefficient $\gamma_{j}$ [23]:

$$
\gamma_{j}=\frac{\sqrt{\sum_{i=1}^{n}\left(x_{i j}-(1 / n) \sum_{i=1}^{n} x_{i j}\right)^{2}(1 / n)}}{\left((1 / n) \sum_{i=1}^{n} x_{i j}\right)} .
$$

Step 2. Calculating the variation coefficient weight $\alpha_{j}$ [23]:

$$
\alpha_{j}=\frac{\gamma_{j}}{\sum_{j=1}^{m} \gamma_{j}}
$$

\subsection{Multidimensional Combination Weighting Model Based} on Variance Maximization. The credit evaluation for a limited number of evaluation objects is essentially a ranking and comparison of the comprehensive evaluation results of all evaluation objects. The importance of the index is judged according to the difference between indices; that is to say, the greater difference of the data of the index leads to the higher importance. Therefore, if the data difference of all evaluation objects on the same index is smaller, the index plays a smaller role in the evaluation ranking results and will be given a smaller weight; conversely, if the numerical difference of all evaluation objects on the same index is greater, the index should be given the greater weight. Besides, if there is no numerical difference of all evaluation objects on a certain index, it can be seen that the index does not affect the ranking result of credit evaluation, and the weight of the index is 0 .
Variance is an important factor to reflect the difference, so this paper uses the variance maximization of normalized constraints to construct a multidimensional combination weighting model, in which the combined weight of all indicators has the largest total variance of all evaluation objects. The entropy, CRITIC, and variation coefficients are combined to determine the weight of the index from three dimensions of information, volatility, and difference of the data, and the optimal combination weight is calculated by the multidimensional combination weighting model.

$$
\text { Let } \quad G=\left(x_{1}, x_{2}, \ldots, x_{m}\right), \quad U=\left(u_{1}, u_{2}, \ldots, u_{n}\right) \text {, }
$$
and $y_{i j}=u_{j}\left(g_{i}\right)(i=1,2, \ldots, m ; j=1,2, \ldots, n)$ be the set of evaluation objects, the set of evaluation indicators, and the score of the evaluation object $g_{i}$ on the index $u_{j} . x_{i j}$ is the standardized score of the $j$ th evaluation object on the $i$ th index.

Let $w_{j}, w_{j}^{k}$, and $\alpha_{k}$ be the combined weights, the weights of three single weighting models, and the linear coefficient of the combined weights. Note that $\sum_{k=1}^{3} \alpha_{k}^{2}=1$, and the combination weighting model is established based on the principle of maximizing the variance of the indicators, shown as follows:

$$
\begin{aligned}
& \max F=\sum_{j=1}^{n} \sum_{i=1}^{m}\left(x_{i j}-\overline{x_{i j}}\right)^{2} w_{j} \\
& \text { s.t. }\left\{\begin{array}{l}
w_{j}=\sum_{k=1}^{3} \alpha_{k} w_{j}^{k} \\
\sum_{k=1}^{3} \alpha_{k}^{2}=1 \\
0<\alpha_{k}<1, \quad k=1,2,3 .
\end{array}\right.
\end{aligned}
$$


The Lagrange extreme value method is used to solve the model, and the Lagrange function is shown as

$$
L=\sum_{j=1}^{n} \sum_{i=1}^{m} \sum_{k=1}^{3}\left(x_{i j}-\overline{x_{i j}}\right)^{2}\left(\alpha_{k} w_{j}^{k}\right)-\lambda\left(\sum_{k=1}^{3} \alpha_{k}^{2}-1\right) .
$$

Note that $\lambda$ is the Lagrange multiplier, and $\left(\partial L / \partial \alpha_{k}\right)=0$ $(k=1,2,3)$. Then, two Lagrangian constraints are obtained, as shown in the following:

$$
\left\{\begin{array}{l}
\sum_{j=1}^{n} \sum_{i=1}^{m}\left(x_{i j}-\overline{x_{i j}}\right)^{2} w_{j}^{k}-2 \lambda \alpha_{k}=0 \\
\sum_{k=1}^{3} \alpha_{k}^{2}-1=0
\end{array}\right.
$$

where $\alpha_{k}^{*}(k=1,2,3)$ is calculated using the following equation:

$$
\alpha_{k}^{*}=\frac{\sum_{j=1}^{n} \sum_{i=1}^{m}\left(x_{i j}-\overline{x_{i j}}\right)^{2} w_{j}^{k}}{\sqrt{\sum_{k=1}^{3} \sum_{j=1}^{n} \sum_{i=1}^{m}\left(x_{i j}-\overline{x_{i j}}\right)^{2} w_{j}^{k}\left(\sum_{j=1}^{n} \sum_{i=1}^{m}\left(x_{i j}-\overline{x_{i j}}\right)^{2} w_{j}^{k}\right)^{2}}}
$$

The normalized value of $\alpha_{k}^{*}$ is calculated, as shown in the following equation:

$$
\alpha_{k}=\frac{\alpha_{k}^{*}}{\sum_{k=1}^{3} \alpha_{k}^{*}}
$$

The normalized combination weights $w_{j}$ can be calculated through equation (8), and the combined evaluation results are calculated according to the combination weights, as shown in the following equation:

$$
G=\sum_{j=1}^{n} w_{j} x_{i j}
$$

\section{Empirical Study}

3.1. Determination of Evaluation Index System. The construction of the credit evaluation system of the road transport industry fully takes the characteristics of the industry into account and follows the principles of data availability and scientific. The selection of evaluation indicators is universal and comparable, not only paying attention to the indicators that affect credit performance but also considering the safety production capacity and the basic quality of enterprises that affect the safety of road transport. According to the observable principle, the data categories that cannot be quantified in the primary index are deleted to ensure that the credit evaluation model can be applied in practice.

The credit evaluation index system of road transport enterprises is constructed from four criteria: enterprise basic quality, enterprise management qualification, enterprise safety production, and enterprise credit management. The enterprise basic quality includes the establishment time of the enterprise, the validity period of the business license, the permit status, and other indicators. The enterprise management qualification includes the enterprise grade and examination and approval category index and other indicators. The enterprise safety production includes indicators such as vehicle technical level, whether the vehicle is equipped with a satellite positioning terminal with travel recorder function, and the enterprise credit management includes enterprise assessment level and assessment year.

3.2. Samples and Data Source. The samples of this paper are road transport enterprises including passenger transport companies, taxi companies, and logistic transport companies. The empirical data are collected from the credit information database of road transportation in a certain province of China, including 115 road transport enterprises. For the sake of data confidentiality, the specific enterprise names are removed in this paper. This paper used three types of indicators involving positive indicators, negative indicators, and qualitative indicators, and a scoring standard is established to score the qualitative indicators.

\subsection{Data Processing}

3.3.1. Data Standardization. The types of indicators include positive indicators, negative indicators, and qualitative indicators. Positive indicators are those for which larger values are better, such as "enterprise grade," and negative indicators are those for which smaller values are better, such as "assessment grade."

Let $x_{i j}$ represent the standard score of the $j$ th evaluation object on the $i$ th index. Let $v_{i j}$ represent the original data of the $j$ th evaluation object on the $i$ th index. $n$ represents the total number of evaluation objects. The standardization equations of the positive index and negative index are as follows [24]:

$$
\begin{aligned}
& x_{i j}=\frac{v_{i j}-\min _{1 \leq j \leq n}\left(v_{i j}\right)}{\max _{1 \leq j \leq n}\left(v_{i j}\right)-\min _{1 \leq j \leq n}\left(v_{i j}\right)}, \\
& x_{i j}=\frac{\max _{1 \leq j \leq n}\left(v_{i j}\right)-v_{i j}}{\max _{1 \leq j \leq n}\left(v_{i j}\right)-\min _{1 \leq j \leq n}\left(v_{i j}\right)} .
\end{aligned}
$$

For the qualitative indicators, we establish a scoring standard to convert the data of qualitative indicators into the 
number in the interval of $[0,1]$. The scoring criteria of the qualitative indicators are shown in Table 1.

3.3.2. Indicator Screening. We screen the standardized indicators and delete the indicators that reflect duplicate information. The correlation coefficient is calculated between any two indicators in the same criterion layer, and the correlation analysis is not calculated for indicators between different criterion layers since the indicators with different meanings cannot replace each other even if those data are related. Let $w_{i j}, z_{k i}$, and $\overline{Z_{i}}$ be the correlation coefficient between the $i$ th index and the $j$ th index, the score of the $k$ th evaluation object on the $i$ th index, and the mean score of the $i$ th index. Thus, the correlation coefficient between indicators is calculated using the following equation [22]:

$$
w_{i j}=\frac{\sum_{k=1}^{n}\left(Z_{k i}-\bar{Z}_{i}\right)\left(Z_{k i}-\bar{Z}_{j}\right)}{\sqrt{\sum_{k=1}^{n}\left(Z_{k i}-\bar{Z}_{i}\right)^{2}\left(Z_{k i}-\bar{Z}_{j}\right)^{2}}} .
$$

Set a critical value $M(0<M<1)$. If $\left|w_{i j}\right|>M$, delete one of the indicators; if $\left|w_{i j}\right|<M$, retain two indicators. The critical value $M$ in this paper is set to 0.8 .

The standardized data $x_{i j}$ and $x_{v j}$ of the same criterion layer are brought in equation (15), and four correlation coefficient matrices are obtained. Among them, the correlation coefficient between the index "reputation assessment grade" and the index "reputation assessment year" is -0.804 , thus $\left|w_{1516}\right|>0.8$, which indicates that the two indicators are significantly related. The index "reputation assessment grade" is of greater practical significance in the credit evaluation, so the index "reputation assessment year" is deleted. The final evaluation indicators and standardization results are shown in Table 2.

3.4. Calculation of Multidimensional Single Weight. The multidimensional single weights of entropy, CRITIC, and variation coefficient are calculated. The results are shown in Table 3.

According to the calculation results, the entropy values are all greater than $0.9 .80 \%$ of the entropy values are more than 0.95 , which means that the entropy weight can reflect most of the original information of the evaluation system. The amount of information of the CRITIC of the index "enterprise management grade" is 5.7, which is the largest of all.

\subsection{Calculation of Evaluation Results of Combination} Weighting Model. The weights of the combined weighting model are calculated. The comparison of the results of three objective weighting methods and the combination weighting method are shown in Table 4 and Figure 2.

According to the comparison diagram, we can see that the weights of three single weighting models and the combined weighting model are generally the same, and there are differences between the weights of some indicators. The weights of the combination weighting model are at an equilibrium level of the weights of three single weighting models, which achieves the complementary advantages of the three models.

The evaluation scores are calculated by the weights of three single objective weighting methods and the combination weighting method, respectively. According to the unified rating method, " $5 \mathrm{C}$ " of the transportation industry [25], the credit grades of the enterprises are divided into five grades: AA, A, B, C, and D, and the final evaluation results are shown in Table 5.

According to the evaluation results, the credit rating of road transport enterprises in the province of China is generally $\mathrm{B}$ and $\mathrm{C}$, and there is no enterprise whose credit rating is $\mathrm{D}$ and $\mathrm{AA}$. It can be seen that the credit situation of road transport enterprises in the province is at a medium level and can be further improved.

3.6. The Rationality Test. In order to verify whether the score and ranking of the combination weighting model can better reflect the advantages and characteristics of the three single weighting methods, this paper conducts the cosine value test, the Euclidean distance test, and the order preservation test. The comparison results of the rationality test are shown in Tables 6-8.

According to Table 6, the sum of cosine results between the combination weighting method and three single weighting methods is 3.871 , which is the highest, so the similarity between the combination weighting method and the three single weighting methods is the highest.

Table 7 shows that, in the Euclidean distance test, the sum of the Euclidean distance between the combination weighting method and the other three methods is the smallest, which is 247.948, thus its consistency is the highest.

According to Table 8, in the order preservation test, the summary result between the combination weighting method and three single weighting methods is up to 36 , so the combination weighting method has the best consistency with the other three methods.

Through the rationality test of the model, the test result of the combined weighting model is the best, which proves that the combined weighting model is feasible and scientific.

\section{Analysis of the Empirical Results}

Based on the analysis of the information volume, volatility, and difference of sample data, the results of the rationality test of entropy and variation coefficient are relatively good, while the rationality test of CRITIC is relatively poor. Through the test results, we can see that the volatility of the samples is weak, and hence the data structure is relatively stable.

According to the credit rating results of road transportation enterprises, $10 \%$ of the enterprises have a credit rating of $A, 72 \%$ of the enterprises have a credit rating of $B$, $18 \%$ of them have a credit rating of $C$, and those with a credit rating of $A A$ and $D$ are 0 . It can be seen that the credit level of road transport enterprises in a certain province of China is at a medium level. The order according to the weights of the criterion layers is as follows: enterprise management 
TABLE 1: Scoring criterion of qualitative indicators.

\begin{tabular}{|c|c|c|c|}
\hline (1) Criterion layer & (2) Indices & (3) Scoring options & (4) Scoring \\
\hline \multirow{5}{*}{ (2) Safety production } & (1) Whether to install satellite positioning & $\begin{array}{l}\text { (1) No or data missing } \\
\text { (2) Yes }\end{array}$ & $\begin{array}{l}0.00 \\
1.00\end{array}$ \\
\hline & $\ldots$ & -. & $\ldots$ \\
\hline & \multirow{3}{*}{ (4) Vehicle operating status } & (1) Scrapped or data missing & 0.00 \\
\hline & & (2) Outage & 0.50 \\
\hline & & (3) Operation & 1.00 \\
\hline$\cdots$ & $\cdots$ & $\cdots$ & $\cdots$ \\
\hline \multirow{2}{*}{ (4) Management qualification } & \multirow{2}{*}{ (1) Administrative license approval category } & (1) General & 0.50 \\
\hline & & (2) Accreditation registration & 1.00 \\
\hline$\cdots$ & $\cdots$ & $\cdots$ & $\ldots$ \\
\hline
\end{tabular}

TABLE 2: Evaluation index data of road transportation enterprises.

\begin{tabular}{|c|c|c|c|c|c|c|c|c|c|}
\hline $\begin{array}{l}\text { (a) } \\
\text { Number }\end{array}$ & $\begin{array}{l}\text { (b) Criterion } \\
\text { layer }\end{array}$ & (c) Indices & $\begin{array}{l}\text { (d) Type of } \\
\text { index }\end{array}$ & $\begin{array}{l}\text { (1) } \\
\text { Company } 1\end{array}$ & 115 & $\begin{array}{l}\text { (115) Company } \\
115\end{array}$ & $\begin{array}{l}\text { Standardized } \\
\text { enterprises } x \\
(116) \\
\text { Company } 1\end{array}$ & $\cdots$ & $\begin{array}{l}\text { a of } 115 \\
(230) \\
\text { Company } \\
115\end{array}$ \\
\hline 1 & (1) Basic quality & (1) Establishment time & Positive & 13 & $\cdots$ & 4 & 0.5238 & $\cdots$ & 0.0952 \\
\hline$\cdots$ & (1) Daste quanty & $\cdots$ & $\ldots$ & $\cdots$ & $\cdots$ & $\cdots$ & $\cdots$ & $\cdots$ & $\cdots$ \\
\hline 4 & $\begin{array}{l}\text { (2) Management } \\
\text { qualification }\end{array}$ & $\begin{array}{l}\text { (4) Administrative } \\
\text { license approval } \\
\text { category }\end{array}$ & Qualitative & Ordinary & $\ldots$ & $\begin{array}{l}\text { Identification and } \\
\text { registration }\end{array}$ & 0.5 & $\cdots$ & 1 \\
\hline$\cdots$ & & $\cdots$ & $\cdots$ & $\cdots$ & $\cdots$ & $\cdots$ & $\cdots$ & $\cdots$ & $\cdots$ \\
\hline 10 & $\begin{array}{l}\text { (3) Safety } \\
\text { production }\end{array}$ & $\begin{array}{l}\text { (10) Vehicle technical } \\
\text { grade }\end{array}$ & Negative & 1 & $\cdots$ & 2 & 1 & $\cdots$ & 0.5 \\
\hline 15 & $\begin{array}{l}\text { (4) Credit } \\
\text { management }\end{array}$ & $\begin{array}{l}\text { (15) Reputation } \\
\text { assessment grade }\end{array}$ & Negative & 1 & $\cdots$ & 2 & 1 & $\cdots$ & 0.5 \\
\hline
\end{tabular}

TABLE 3: Weights of multidimensional single weighting methods.

\begin{tabular}{|c|c|c|c|c|c|c|c|c|}
\hline \multirow[b]{2}{*}{$\begin{array}{l}\text { (1) } \\
\text { Number }\end{array}$} & \multirow[b]{2}{*}{$\begin{array}{l}\text { (2) Criterion } \\
\text { layer }\end{array}$} & \multirow[b]{2}{*}{ (3) Indices } & \multicolumn{2}{|c|}{ Entropy } & \multicolumn{2}{|l|}{ CRITIC } & \multicolumn{2}{|c|}{ Variation coefficient } \\
\hline & & & $\begin{array}{l}(4) \\
\text { Entropy } \\
\text { value }\end{array}$ & $\begin{array}{c}(5) \\
\text { Weight }\end{array}$ & $\begin{array}{l}\text { (6) The amount } \\
\text { of information }\end{array}$ & $\begin{array}{c}(7) \\
\text { Weight }\end{array}$ & $\begin{array}{l}\text { (8) Variation } \\
\text { coefficient }\end{array}$ & $\begin{array}{c}(9) \\
\text { Weight }\end{array}$ \\
\hline 1 & & (1) Establishment time & 0.9408 & 0.1431 & 3.4207 & 0.0850 & 0.8019 & 0.1168 \\
\hline$\cdots$ & Basic quality & $\cdots$ & $\cdots$ & $\ldots$ & $\cdots$ & $\cdots$ & $\cdots$ & $\ldots$ \\
\hline 4 & $\begin{array}{l}\text { Management } \\
\text { qualification }\end{array}$ & $\begin{array}{l}\text { (4) Administrative license } \\
\text { approval category }\end{array}$ & 0.9986 & 0.0033 & 0.7836 & 0.0195 & 0.1290 & 0.0188 \\
\hline$\cdots$ & & $\cdots$ & $\cdots$ & $\cdots$ & $\cdots$ & $\cdots$ & $\cdots$ & $\cdots$ \\
\hline 11 & $\begin{array}{c}\text { Safety } \\
\text { production }\end{array}$ & $\begin{array}{l}\text { (11) Whether the vehicle is } \\
\text { equipped with satellite } \\
\text { positioning }\end{array}$ & 0.9791 & 0.0505 & 3.8378 & 0.0954 & 0.3427 & 0.0499 \\
\hline$\cdots$ & & $\cdots$ & $\cdots$ & $\cdots$ & $\cdots$ & $\cdots$ & $\cdots$ & $\cdots$ \\
\hline 15 & $\begin{array}{c}\text { Credit } \\
\text { management }\end{array}$ & $\begin{array}{l}\text { (15) Reputation assessment } \\
\text { grade }\end{array}$ & 0.9858 & 0.0343 & 3.5595 & 0.0885 & 0.3640 & 0.0530 \\
\hline
\end{tabular}

qualification $>$ enterprise safety production $>$ enterprise basic quality $>$ enterprise credit management. Among them, the weight of enterprise management qualification is 0.3939 , which is the highest of all criterion layers, occupying an important proportion in the evaluation model. Thus, enterprise management qualification is an important factor affecting the evaluation results of road transport enterprises. It reflects the administrative license and management ability and so on of the enterprises through the credit qualification examination. The examination of the enterprise management qualification can eliminate the enterprises that do not meet the qualification requirements, to protect the interests of consumers and reduce the risk of default. The enterprise safety production also has an important impact on the credit evaluation of road transport enterprises, and the weight of the enterprise safety production is 0.335 . Production safety is a special factor for road transport enterprises. The production safety status of road transport enterprises has an 
TABLE 4: Weights of the three objective weighting methods and the combination weighting method.

\begin{tabular}{|c|c|c|c|c|c|c|c|}
\hline $\begin{array}{l}\text { (1) } \\
\text { Number }\end{array}$ & (2) Criterion layer & (3) Indices & $\begin{array}{c}(4) \\
\text { Variance }\end{array}$ & $\begin{array}{l}\text { (5) Entropy } \\
\text { weight } w_{j}^{1}\end{array}$ & $\begin{array}{l}\text { (6) CRITIC } \\
\text { weight } w_{j}^{2}\end{array}$ & $\begin{array}{c}\text { (7) Variation } \\
\text { coefficient weight } \\
w_{j}^{3}\end{array}$ & $\begin{array}{l}\text { (8) Combined } \\
\text { weight } w_{j}\end{array}$ \\
\hline 1 & \multirow{2}{*}{ Basic quality } & Establishment time & 0.0612 & 0.1431 & 0.0850 & 0.1168 & 0.1151 \\
\hline$\cdots$ & & $\cdots$ & $\cdots$ & $\cdots$ & $\cdots$ & $\cdots$ & $\cdots$ \\
\hline 4 & \multirow{2}{*}{$\begin{array}{l}\text { Management } \\
\text { qualification }\end{array}$} & $\begin{array}{l}\text { Administrative license } \\
\text { approval category }\end{array}$ & 0.0043 & 0.0033 & 0.0195 & 0.0188 & 0.0135 \\
\hline$\cdots$ & & $\cdots$ & & $\ldots$ & $\ldots$ & $\cdots$ & \\
\hline 11 & Safety production & $\begin{array}{l}\text { Whether the vehicle is } \\
\text { equipped with satellite } \\
\text { positioning }\end{array}$ & 0.0943 & 0.0505 & 0.0954 & 0.0499 & 0.0660 \\
\hline$\cdots$ & & $\cdots$ & $\cdots$ & $\cdots$ & $\cdots$ & $\cdots$ & $\cdots$ \\
\hline 15 & $\begin{array}{c}\text { Credit } \\
\text { management }\end{array}$ & $\begin{array}{c}\text { Reputation assessment } \\
\text { grade }\end{array}$ & 0.0649 & 0.0343 & 0.0885 & 0.0530 & 0.0587 \\
\hline 16 & $\begin{array}{c}\text { Combined weight } \\
\text { coefficient } \alpha_{k}\end{array}$ & - & 0.3562 & 0.3492 & 0.2946 & - & \\
\hline
\end{tabular}

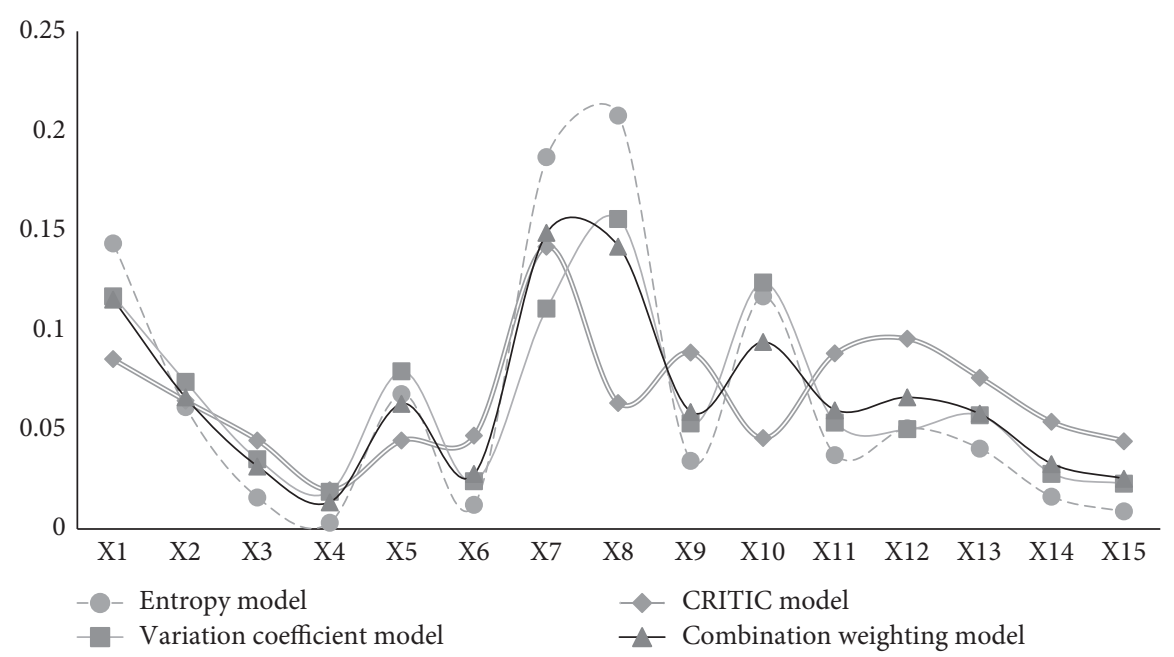

FIGURE 2: Comparison of weights of various weighting models.

TABLE 5: Credit evaluation results of road transportation enterprises.

(1) Enterprise (2) Entropy score (3) CRITIC score (4) Variation coefficient score

Combination weighting
based on maximum
$\begin{array}{cc}\text { variance } & \text { (7) Credit grade }\end{array}$

(5) Score (6) Ranking

\begin{tabular}{|c|c|c|c|c|c|c|}
\hline Company 1 & 33.9418 & 59.0575 & 43.2482 & 45.4536 & 76 & B \\
\hline$\ldots$ & $\ldots$ & $\ldots$ & $\ldots$ & $\ldots$ & $\ldots$ & $\ldots$ \\
\hline Company 4 & 19.5441 & 36.5340 & 27.8106 & 27.9120 & 115 & $\mathrm{C}$ \\
\hline$\ldots$ & $\ldots$ & $\ldots$ & $\ldots$ & $\ldots$ & $\ldots$ & ... \\
\hline Company 51 & 55.8718 & 72.0974 & 56.9767 & 61.8633 & 7 & A \\
\hline$\ldots$ & $\ldots$ & $\ldots$ & $\ldots$ & $\ldots$ & $\ldots$ & $\ldots$ \\
\hline Company 74 & 45.1164 & 63.8633 & 46.3337 & 52.0214 & 44 & B \\
\hline$\ldots$ & $\ldots$ & $\ldots$ & $\ldots$ & $\ldots$ & $\ldots$ & $\ldots$ \\
\hline Company 115 & 42.6986 & 59.3056 & 42.7035 & 48.4992 & 63 & $\mathrm{~B}$ \\
\hline
\end{tabular}

TABLE 6: Cosine test of different kinds of weighting models.

\begin{tabular}{|c|c|c|c|c|c|}
\hline & Entropy model & CRITIC model & Variation coefficient model & Combination weighting model & Summary \\
\hline Entropy model & 1 & 0.802 & 0.961 & 0.969 & 3.732 \\
\hline CRITIC model & 0.802 & 1 & 0.859 & 0.92 & 3.581 \\
\hline Variation coefficient model & 0.961 & 0.859 & 1 & 0.982 & 3.802 \\
\hline Combination weighting model & 0.969 & 0.92 & 0.982 & 1 & 3.871 \\
\hline
\end{tabular}


TABLE 7: Euclidean distance test of different kinds of weighting models.

\begin{tabular}{|c|c|c|c|c|c|}
\hline & Entropy model & CRITIC model & Variation coefficient model & Combination weighting model & Summary \\
\hline Entropy model & 0 & 202.725 & 57.831 & 85.274 & 345.83 \\
\hline CRITIC model & 202.725 & 0 & 159.026 & 118.427 & 480.178 \\
\hline Variation coefficient model & 57.831 & 159.026 & 0 & 44.247 & 261.104 \\
\hline Combination weighting model & 85.274 & 118.427 & 44.247 & 0 & 247.948 \\
\hline
\end{tabular}

TABLE 8: Order preservation test of different kinds of weighting models.

\begin{tabular}{lccccc}
\hline & Entropy model & CRITIC model & Variation coefficient model & Combination weighting model & Summary \\
\hline Entropy model & 0 & 1 & 12 & 18 & 31 \\
CRITIC model & 1 & 0 & 1 & 0 & 2 \\
Variation coefficient model & 12 & 1 & 16 & 16 & 29 \\
Combination weighting model & 18 & 2 & 0 & 36 \\
\hline
\end{tabular}

important impact on the credit performance of enterprises and directly affects the reputation and development of enterprises.

Through the analysis of the weights of the criterion layers, we can optimize the important criterion layers of the credit evaluation system, which can significantly contribute to the evaluation results of the road transport enterprises. In other words, strengthening the credit qualification examination and improving the safety production capacity of enterprises can further improve the credit level and enhance the market competitiveness of the enterprises.

\section{Conclusions and Prospects}

This paper proposed a multidimensional combination weighting model based on variance maximization. Three objective weighting models, entropy, CRITIC, and variation coefficient methods, were used to determine the single weight from three dimensions of information volume, volatility, and difference, and then a combination weighting model was constructed by combining three single weighting methods to determine the combination weights based on the principle of maximizing the total variance of all evaluation indicators for all evaluation objects. The new model makes up for the deviation of the single weighting method and fills the gap in the existing road transportation enterprise credit evaluation methods.

The combination weight is obtained through an optimized mathematical model, which is easy to implement on a computer. The empirical results also prove the effectiveness and feasibility of the combination weighting model. The results show that the credit data of road transport enterprises in a certain province of China are relatively stable, and the credit level of most enterprises is at the middle level. The management qualification and safety production capacity account for a high proportion in the credit evaluation model of road transport enterprises, and hence they have a great impact on the credit level of the enterprises. Thus, strengthening the examination of the management qualification and the supervision of the safety production capacity can further improve the credit level of road transport enterprises.
The multidimensional combination weighting model proposed in this paper is highly operable and has important promotion and application value. In terms of extension, the model proposed in this paper can be applied to multiattribute decision-making in engineering, society, economy, management, and so on, providing a problem-solving model for the multiattribute decision-making of other projects. The follow-up study considers introducing the regional economic development index into the credit evaluation system to uniformly evaluate the credit level of road transport enterprises in different regions to achieve effective mutual recognition of the credit evaluation results and improve the consistency of various credit evaluation systems.

\section{Data Availability}

The data come from the national database and cannot be shared due to confidentiality.

\section{Conflicts of Interest}

The authors declare that they have no conflicts of interest.

\section{References}

[1] Standard \& Poor's, General Criteria: Principles of Credit Ratings, Standard \& Poor's, New York, NY, USA, 2011.

[2] Moody's, Global Business \& Consumer Service Industry Rating Methodology, Moody's, New York, NY, USA, 2013.

[3] K.-H. Lee, H. Sapriza, and G. A. Suarez, "Sovereign credit risk, banks' government support, and bank stock returns around the world," Journal of Money, Credit and Banking, vol. 46, no. 1, pp. 93-121, 2014

[4] J.-M. Li, J.-Y. Wu, J.-L. Zhang, and L.-M. Ke, "Study on SMEs credit evaluation system in E-commerce environment," Systems Engineering-Theory \& Practice, vol. 32, no. 3, pp. 555560, 2012.

[5] K. K. F. Yuen, "Fuzzy cognitive network process: comparisons with fuzzy analytic hierarchy process in new product development strategy," IEEE Transactions on Fuzzy Systems, vol. 22, no. 3, pp. 597-610, 2014.

[6] G. van de Kaa, E. van Heck, H. J. de Vries, J. van den Ende, and J. Rezaei, "Supporting decision making in technology standards battles based on a fuzzy analytic hierarchy process," 
IEEE Transactions on Engineering Management, vol. 61, no. 2, pp. 336-348, 2014.

[7] T. N. Le, H. A. Quyen, and N. A. Nguyen, "Application of fuzzy-analytic hierarchy process algorithm and fuzzy load profile for load shedding in power systems," International Journal of Electrical Power \& Energy Systems, vol. 77, pp. 178-184, 2016.

[8] Y. Li, Y.-H. Li, Z.-J. Han, G.-Q. Li, K. Gao, and Z.-H. Wang, "Determination of optimal opening scheme for electromagnetic loop networks based on fuzzy analytic hierarchy process," Mathematical Problems in Engineering, vol. 2016, Article ID 3965608, 11 pages, 2016.

[9] G. W. Fischer, "Range sensitivity of attribute weights in multiattribute value model," Organizational Behavior and Human Decision Processes, vol. 62, pp. 52-66, 1995.

[10] B. Mareschal, "Weight stability intervals in multicriteria decision aid," European Journal of Operational Research, vol. 33, no. 1 , pp. 54-64, 1988.

[11] E. Triantaphyllou and A. Sánchez, "A sensitivity analysis approach for some deterministic multi-criteria decisionmaking methods," Decision Sciences, vol. 28, no. 1, pp. 151-194, 1997.

[12] S. Zhang, M. Zhang, and G.-T. Chi, "The science and technology evaluation model based on entropy weight and empirical research during the 10th five-year of China," Chinese Journal of Management, vol. 7, no. 1, pp. 34-42, 2010.

[13] F.-S. Meng and M.-Y. Li, "Research on evaluation of energy efficiency and influence factors in China based on optimal combination weights," Operations Research and Management Science, vol. 22, no. 6, pp. 153-160, 2013.

[14] H.-D. Zhao, S.-X. Guan, and Y.-E. Bao, "Interval multiple attribute decision making method based on combination weighting," Statistics \& Decision, vol. 19, pp. 98-101, 2012.

[15] S. Chao and X.-S. Fu, "Research on different weight combination in air quality forecasting models," Journal of Cleaner Production, vol. 261, 2020.

[16] X.-H. Chen and Z.-H. Yang, "The study of credit evaluation system based on improved fuzzy evaluation method," Chinese Journal of Management Science, vol. 23, no. 1, pp. 146-153, 2015.

[17] Y. Li, J.-L. Wang, D.-B. Zhao, G.-Q. Li, and C. Chen, "A two stage approach for combined heat and power economic emission dispatch: combining multi objective optimization with integrated decision making," Energy, vol. 162, no. 1, pp. 237-254, 2018.

[18] H.-Y. Chen, "Research on optimal combination determining weights method for multiple attribute decision making," Operations Research and Management Science, vol. 2, pp. 6$10,2003$.

[19] Y. Sun and X.-Z. Bao, "A new combination weighting method and its application based on maximizing deviations," Chinese Journal of Management Science, vol. 19, no. 6, pp. 141-148, 2011.

[20] G.-T. Chi, F. Qi, and N. Zhang, “The city's ecosystem evaluation model based on optimal combination weights and its application," Operations Research and Management Science, vol. 21, no. 2, pp. 183-191, 2012.

[21] A. Shanian and O. Savadogo, "A methodological concept for material selection of highly sensitive components based on multiple criteria decision analysis," Expert Systems with Applications, vol. 36, no. 2, pp. 1362-1370, 2009.

[22] W. Wang, "Risk evaluation of China's P2P online lending platform-based on entropy weight method and CRITIC method," Financial Theory \& Practice, vol. 12, pp. 54-58, 2016.
[23] Y.-C. Zhu, "Hybrid cross weighting method based on coefficient of variation-G1 method," Statistics \& Decision, vol. 12, pp. 78-81, 2017.

[24] Z.-j. Li, G.-T. Chi, and Z.-d. Xu, "Measurement model of project risks of commercial banks based on combination weighting," Industrial Engineering and Engineering Management, vol. 6, pp. 499-509, 2013.

[25] S.-D. Zuo, "The transportation industry first implemented a unified credit rating," Pearl River Water Transport, vol. 10, p. 40, 2015. 